\title{
Speed Tracking and Synchronization of a Dual-Motor System via Second Order Sliding Mode Control
}

\author{
Wei Chen, Yifei Wu, Renhui Du, Qingwei Chen, and Xiaobei Wu \\ School of Automation, Nanjing University of Science and Technology, Nanjing 210094, China \\ Correspondence should be addressed to Yifei Wu; wuyifei091@163.com
}

Received 6 May 2013; Revised 23 July 2013; Accepted 1 August 2013

Academic Editor: Rongni Yang

Copyright (C) 2013 Wei Chen et al. This is an open access article distributed under the Creative Commons Attribution License, which permits unrestricted use, distribution, and reproduction in any medium, provided the original work is properly cited.

\begin{abstract}
Dual-motor systems have been widely used in industrial applications, and speed synchronization of the motors can always be deteriorated by system parameter uncertainties and load torque perturbations. In this paper, a new robust control strategy for the dual-motor systems is developed by incorporating second order sliding mode control (2-SMC) techniques. The strategy is to design chatting-free control laws to stabilize speed tracking of each motor while synchronizing their velocity. In the proposed scheme, firstly, speed controller for a single motor is designed to eliminate the effects of system parameter variations and load torque perturbations. Secondly, a cross-coupled architecture based synchronous controller is designed to reduce speed error of the motors caused by characteristic inconsistency and unbalanced load torque. Stability of the closed loop system is analyzed by Lyapunov theory; it is proven that both speed tracking errors and synchronous error can converge to zero. Finally, experiments are performed to examine the effectiveness of the developed controllers. Experimental results will show the good performance of the proposed control scheme.
\end{abstract}

\section{Introduction}

In many industrial applications such as reel machines, surface mounting technology (SMT) machines, computer numerical control (CNC) machines, and gantry cranes $[1,2]$, the load is driven by two motors simultaneously. In the running process, the two motors are arranged to track the desired trajectories while keeping their speed the same. Although identical driving equipment would be selected at the design stage, speed tracking and synchronization can always be deteriorated by system parameter variations and load torque perturbations. Poor tracking and synchronization accuracy will lower the quality of work pieces or even result in unusable products $[3,4]$. Hence, with the increasing demands for rapid response and high accuracy, controlling dual-motor system to achieve good speed tracking and synchronization performance while there are various uncertainties and perturbations has become a great challenge in the field of modern manufacture.

The common synchronous control schemes used in the multimotor systems are master-slave method, virtual lineshafting method, and cross-coupled control method [5].
In the master-slave method, slave motor lags behind its master, so there is a large synchronous error during the startup and shutdown periods. Although virtual line-shafting method offers a good degree of speed synchronization of the two motors all the time, there may be a constant steady state error between the reference and the real speed. The cross-coupled control method was initially proposed and successfully applied to CNC biaxis motion control by Koren [6]. Synchronization performance of multiaxis motion was improved by Sun, Barton and Alleyne, and Lin et al. via incorporating adaptive control, iterative learning control, and neural network control into cross-coupled control, respectively [7-9]. In [7], a multiaxis synchronous adaptive controller was developed, the convergence of tracking errors and synchronous errors could be guaranteed. In [8], the problems of single axis tracking and multi-axis synchronization were considered comprehensively, an iterative learning multi-axis controller was designed, and the tracking accuracy of the system was improved. In [9], functional link radial basis function network (FLRBF) was applied to the control of a dualmotor system, weights in the network were optimized online, 
and speed tracking errors and synchronous errors could be reduced simultaneously. Although the control strategy mentioned earlier can make some efforts for the improvement of control accuracy, various system uncertainties and large load perturbations were not taken into consideration.

Sliding mode control (SMC) method has attracted many scholars' attention due to its simplicity and robustness [1014]. In this method, trajectories of the system are forced to slide along the preset manifold, and then the whole system will show the invariance property against parameter variations and external perturbations. Owing to the limited sample frequency and the high gains selected to exceed the boundaries of uncertainties, there is a so called "chatting" phenomenon in the SMC system, which can increase the energy consumption and decrease the performance. A common method to alleviate the effect of chatting is replacing the sign function by saturation function. By incorporating this method, the trajectories of the system are not forced to stay on the manifold but in a boundary layer instead; the accuracy of tracking is not assured anymore. In order to overcome the drawbacks and preserve the advantages of conventional SMC, a high order SMC (HOSMC) scheme has been proposed by Emel'yanov et al. $[15,16]$, in which the discontinuous switching signal is exerted on higher order time derivative of the sliding mode variable. Thus, the control signal is continuous and a better tracking performance can be achieved. HOSMC has already been applied in the area of formation control of robots, yaw control of vehicles, and motion control of servo systems [17-20].

In many dual-motor systems, there are various uncertainties and large load perturbations; these factors can severely decrease the tracking and synchronization performance of the system. Besides, speed chatting is always not allowed in these industrial machines. Moreover, dual-motor systems are usually applied in the industrial fields that have high dynamic performance requirements. The desired trajectories are always unknown and may keep changing continuously in the manufacturing process; the system needs to track them steadily, quickly, and precisely. Conventional control method, PI control method, for example, is easy to be implemented but can not get high dynamic performance, not to mention there are parameter uncertainties and load perturbations. Aiming at the problems mentioned above and in order to design a robust, chatting-free, and easy to be implemented control scheme, which can guarantee both speed tracking and synchronization performance of the motors despite uncertainties and perturbations, a new control method for dual-motor systems is proposed in this paper via incorporating second order sliding mode control (2-SMC) techniques. The motion equation of a permanent magnet synchronous motor (PMSM) under uncertainties is analyzed first, and then speed controller for a single motor is designed to ensure the tracking performance of each axis under large parameter variations and load perturbations. After that, a cross-coupled architecture based synchronous controller is developed to minimize speed difference of the two motors caused by characteristic inconsistency and unbalanced load torque. Next, stability of the closed loop system is analyzed by Lyapunov theory. Finally, experiments are carried out to verify the effectiveness of the proposed scheme. Due to the powerful computing capacity of DSP TMS320F28335, it is not a tough task to realize 2-SM control of the motors in the system. In addition, better performance can be achieved by utilizing this method: the proposed scheme partly eliminates the effects of system parameter uncertainties and large load perturbations, improves the speed tracking and synchronization performance of dualmotor systems, and gives a powerful support for successfully using 2-SMC on engineering control systems.

\section{Problem Statement}

Figure 1 shows the common structure of a typical dualmotor system. As shown in the figure, the upper computer and drives are connected through a network, commands are sent to the drives by the upper computer, each motor's velocity/current information is shared, and the two motors are arranged to run at the same speed and drive load together.

In a dual-motor system, each PMSM's dynamics can be well approximated by the following equation:

$$
J_{i} \frac{\mathrm{d} \omega_{i}}{\mathrm{~d} t}=K_{T i} i_{i q}-B_{i} \omega_{i}-T_{L i}-\Delta T_{L i}
$$

where $i$ is the subscript, $i=1,2$ (hereinafter the same), $J_{i}$ is the overall mechanical inertia at the motor shaft, $\omega_{i}, K_{T i}$, and $i_{i q}$ are angular velocity, torque constant, and $q$ axis current of the motor, respectively and $B_{i}, T_{L i}$, and $\Delta T_{L i}$ are viscous friction coefficient, rated load torque, and disturbing load torque, respectively. Some assumptions for the system parameters and variables are satisfied according to the following items.

Assumption 1. There are known positive constants $J_{i \text { min }}$, $J_{i \text { max }}, K_{T i_{\text {min }}}, K_{T i_{\text {max }}}, B_{i \text { min }}$, and $B_{i \text { max }}$ such that the following inequalities hold: $J_{i \min }<J_{i}<J_{i \max }, K_{T i \min }<K_{T i}<K_{T i \max }$, and $B_{i \min }<B_{i}<B_{i \max }$.

Assumption 2. There are two known constants $T_{i \max } T_{i d \max }$, and the load torque perturbations satisfy the following inequalities: $\left|\Delta T_{L i}\right|<T_{i \max }$ and $\left|\Delta \dot{T}_{L i}\right|<T_{i d \max }$.

Assumption 3. The desired velocity profile $x_{d}$ is sufficiently smooth.

Set $x_{i}=\omega_{i}, u_{i q}=i_{i q}, a_{i}=K_{T 0 i} / J_{0 i}$, and $b_{i}=-T_{L i} / J_{0 i}$, where $K_{T 0 i}$ and $J_{0 i}$ are nominal values of $K_{T i}$ and $J_{i}$; then function (1) can be rewritten as follows:

$$
\dot{x}_{i}=\left(a_{i}+\Delta a_{i}\right) u_{i q}+\left(b_{i}+\Delta b_{i}\right)-\frac{\Delta T_{L i}}{J_{i}}-\frac{B_{i}}{J_{i}} x_{i},
$$

where $\Delta a_{i}$ and $\Delta b_{i}$ are uncertainties of $a_{i}$ and $b_{i}$, respectively, and they satisfy the following inequalities:

$$
\begin{gathered}
\left|\Delta a_{i}\right| \leq\left(\frac{K_{T i \max }}{J_{i \min }}-\frac{K_{T i \min }}{J_{i \max }}\right), \\
\left|\Delta b_{i}\right| \leq\left(\frac{T_{L i}}{J_{i \min }}-\frac{T_{L i}}{J_{i \max }}\right) . \\
\text { Set } w_{i}=\Delta a_{i} u_{i q}+\Delta b_{i}-\frac{\Delta T_{L i}}{J_{i}}-\frac{B_{i}}{J_{i}} x_{i}
\end{gathered}
$$




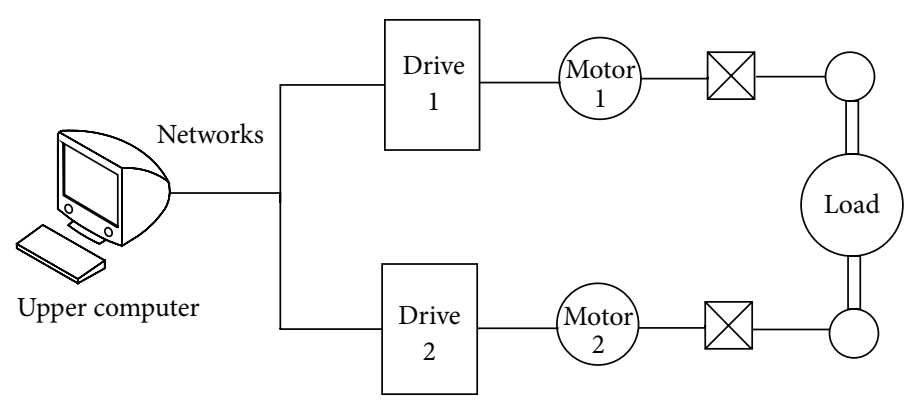

FIGURE 1: Structure of a typical dual-motor system.

where $w_{i}$ denotes the total uncertainties of the dynamics caused by parameter variations and perturbations; then function (2) can be rewritten as follows:

$$
\dot{x}_{i}=a_{i} u_{i q}+b_{i}+w_{i} .
$$

In a real system, due to the restrictions of power supply, the acceleration of the rotor and the upper rate of $i_{i q}$ are limited. So it can be assumed that $\dot{\omega}_{i}$ and $\dot{i}_{i q}$ are in known boundaries; that is, $\left|\dot{\omega}_{i}\right|<\Omega_{d},\left|\dot{i}_{i q}\right|<I_{d}$. On the aforementioned assumption, the inequality $\left|\dot{w}_{i}\right|<\rho_{i 0}$ can be derived, where $\rho_{i 0}=\left(K_{T i \text { max }} / J_{i \text { min }}-K_{T i \text { min }} / J_{i \text { max }}\right) I_{d}+$ $T_{i d m} / J_{i \min }+\left(B_{i \max } / J_{i \min }\right) \Omega_{d}$.

The speed tracking error of a single motor is defined as

$$
e_{i}=x_{i}-x_{d}
$$

The synchronization error is defined as

$$
\varepsilon=x_{1}-x_{2}=e_{1}-e_{2} .
$$

The control task is to design continuous chattering-free control signals $u_{i q}$ which can ensure the convergence of speed tracking error $e_{i}$ and synchronization error $\varepsilon$, that is $\lim _{t \rightarrow \infty}\left|e_{i}\right|=0$ and $\lim _{t \rightarrow \infty}|\varepsilon|=0$, in spite of the parameter uncertainties and external perturbations.

\section{Control System Design and Stability Analysis}

A robust control law with respect to uncertainties and perturbations is needed in the high accuracy speed tracking of the dual-motor system. In this paper, single motor speed controllers and a synchronous controller are developed, respectively. Stability of the closed-loop system is analyzed by Lyapunov theory. Here is the design process in detail.

3.1. Single Motor Speed Controller Design. In order to achieve 2-SM control of sliding variable $e_{i}$, define $\sigma_{i}$ as

$$
\sigma_{i}=\dot{e}_{i}+r e_{i},
$$

where $r$ is a positive constant. When a proper control law that guarantees $\sigma_{i} \dot{\sigma}_{i}<0$ is developed, it can be derived that

$$
\sigma_{i}=\dot{e}_{i}+r e_{i}=0, \quad e_{i}=e_{i}(0) e^{-r t} .
$$

It can be found that the parameter $r$ determines the convergence rate of tracking error. Next is the 2-SM control law for the sliding variable in the form of theorem.

Theorem 4. Consider system (4), satisfying Assumption 1 and Assumption 2 and a smooth speed reference $x_{d}$ satisfying Assumption 3; the speed tracking error fulfills the condition that $\lim _{t \rightarrow \infty}\left|e_{i}\right|=0$ under the control effort of $u_{i}$, and $u_{i}$ is expressed as

$$
\begin{gathered}
u_{i}=u_{i c}+u_{i n}, \\
u_{i c}=\frac{1}{a_{i}}\left(\dot{x}_{d}-b_{i}\right),
\end{gathered}
$$

$$
u_{\text {in }}=-\frac{1}{a_{i}}\left\{r e_{i}+\int\left[k \sigma_{i}+\rho_{i} \operatorname{sgn}\left(\sigma_{i}\right)\right] d t\right\},
$$

where $k$ and $\rho_{i}$ are positive constants, satisfying $k>0, \rho_{i} \geq \rho_{i 0}$. $\operatorname{sgn}(\cdot)$ is the sign function.

Proof of Theorem 4. Choose the following Lyapunov function:

$$
V_{i}=\frac{1}{2} \sigma_{i}^{2}
$$

The time derivative of $V_{i}$ along the system trajectories is expressed as

$$
\dot{V}_{i}=\sigma_{i} \dot{\sigma}_{i}=\sigma_{i}\left(r \dot{e}_{i}+\ddot{e}_{i}\right) .
$$

Differentiating (5) with respect to time along the system trajectories and considering (4) yield

$$
\dot{e}_{i}=a_{i} u_{i}+b_{i}+w_{i}-\dot{x}_{d} .
$$

Considering (9), and (10), (11), one gets

$$
\begin{aligned}
\dot{e}_{i} & =a_{i}\left(u_{i c}+u_{i n}\right)+b_{i}+w_{i}-\dot{x}_{d} \\
& =-r e_{i}-\int\left[k \sigma_{i}+\rho_{i} \operatorname{sgn}\left(\sigma_{i}\right)\right] d t+w_{i} .
\end{aligned}
$$

Differentiating (15) with respect to time along the system trajectories and considering (13) yield

$$
\begin{aligned}
\dot{V}_{i} & =\sigma_{i} \dot{\sigma}_{i}=\sigma_{i}\left[r \dot{e}_{i}-r \dot{e}_{i}-k \sigma_{i}-\rho_{i} \operatorname{sng}\left(\sigma_{i}\right)+\dot{w}_{i}\right] \\
& =-k \sigma_{i}^{2}-\rho_{i}\left|\sigma_{i}\right|+\dot{w}_{i} \sigma_{i} .
\end{aligned}
$$




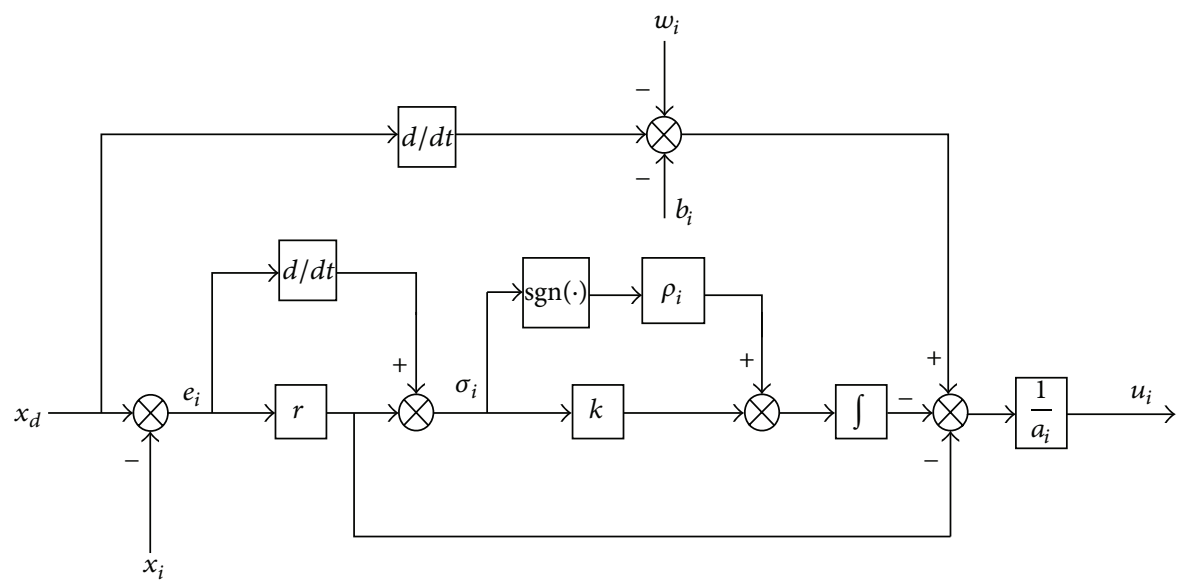

FIgURE 2: Structure of the single motor speed controller.

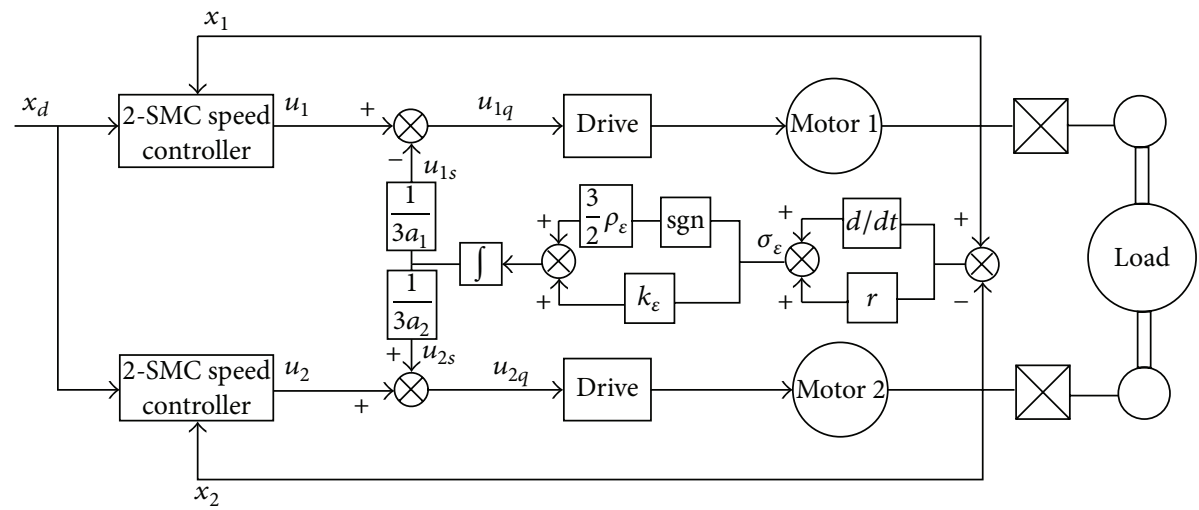

FIGURE 3: Structure of the synchronous controller.

From the analysis in Section 2, one obtains

$$
\sigma_{i} \dot{\sigma}_{i} \leq-k \sigma_{i}^{2}-\rho_{i}\left|\sigma_{i}\right|+\rho_{i 0}\left|\sigma_{i}\right| \leq-k \sigma_{i}^{2} .
$$

Therefore, the system trajectories evolve on the manifold $\{\sigma=0\}$, and $\lim _{t \rightarrow \infty}\left|e_{i}\right|=0$ can be assured.

From Theorem 4, it can be obtained that the speed tracking error can converge to zero in spite of uncertainties and perturbations. The structure of the developed single motor speed controller is shown in Figure 2. The discontinuous control signal is exerted on the second time derivative of sliding variable $e_{i}$, and the control law $u_{i}$ is indeed continuous; therefore the chattering phenomenon can be alleviated.

3.2. Synchronous Controller Design. The synchronous controller is developed on the base of cross-coupled architecture, and the structure of the controller is shown in Figure 3. In order to achieve 2-SM control of sliding variable $\varepsilon, \sigma_{\varepsilon}$ is defined as

$$
\sigma_{\varepsilon}=\dot{\varepsilon}+r \varepsilon \text {. }
$$

Further, one obtains

$$
\sigma_{\varepsilon}=\left(\dot{e}_{1}-\dot{e}_{2}\right)+r\left(e_{1}-e_{2}\right)=\sigma_{1}-\sigma_{2} .
$$

When proper control law is developed, it can be derived that

$$
\sigma_{\varepsilon}=\dot{\varepsilon}+r \varepsilon=0, \quad \varepsilon=\varepsilon(0) \varepsilon^{-r t}
$$

Then the 2-SM synchronous controller is designed as follows:

$$
u_{i s}=(-1)^{i} \frac{1}{3 a_{i}} \int\left[k_{\varepsilon} \sigma_{\varepsilon}+\frac{3}{2} \rho_{\varepsilon} \operatorname{sgn}\left(\sigma_{\varepsilon}\right)\right] d t \text {, }
$$

where $k_{\varepsilon}$ and $\rho_{\varepsilon}$ are constants satisfying $k_{\varepsilon}>0$ and $\rho_{\varepsilon} \geq$ $2\left(\rho_{1}+\rho_{2}\right)$, respectively. The overall control law of each motor is developed as follows:

$$
u_{i q}=u_{i}+u_{i s}
$$

\subsection{Stability Analysis of the System}

Theorem 5. If system (4) satisfies Assumption 1Assumption 3, the control law defined by (9)-(11) and (21)-(22) ensures the convergence of the speed tracking errors and the synchronous error; that is, $\lim _{t \rightarrow \infty}\left|e_{i}\right|=0$ and $\lim _{t \rightarrow \infty}|\mathcal{\varepsilon}|=0$. 


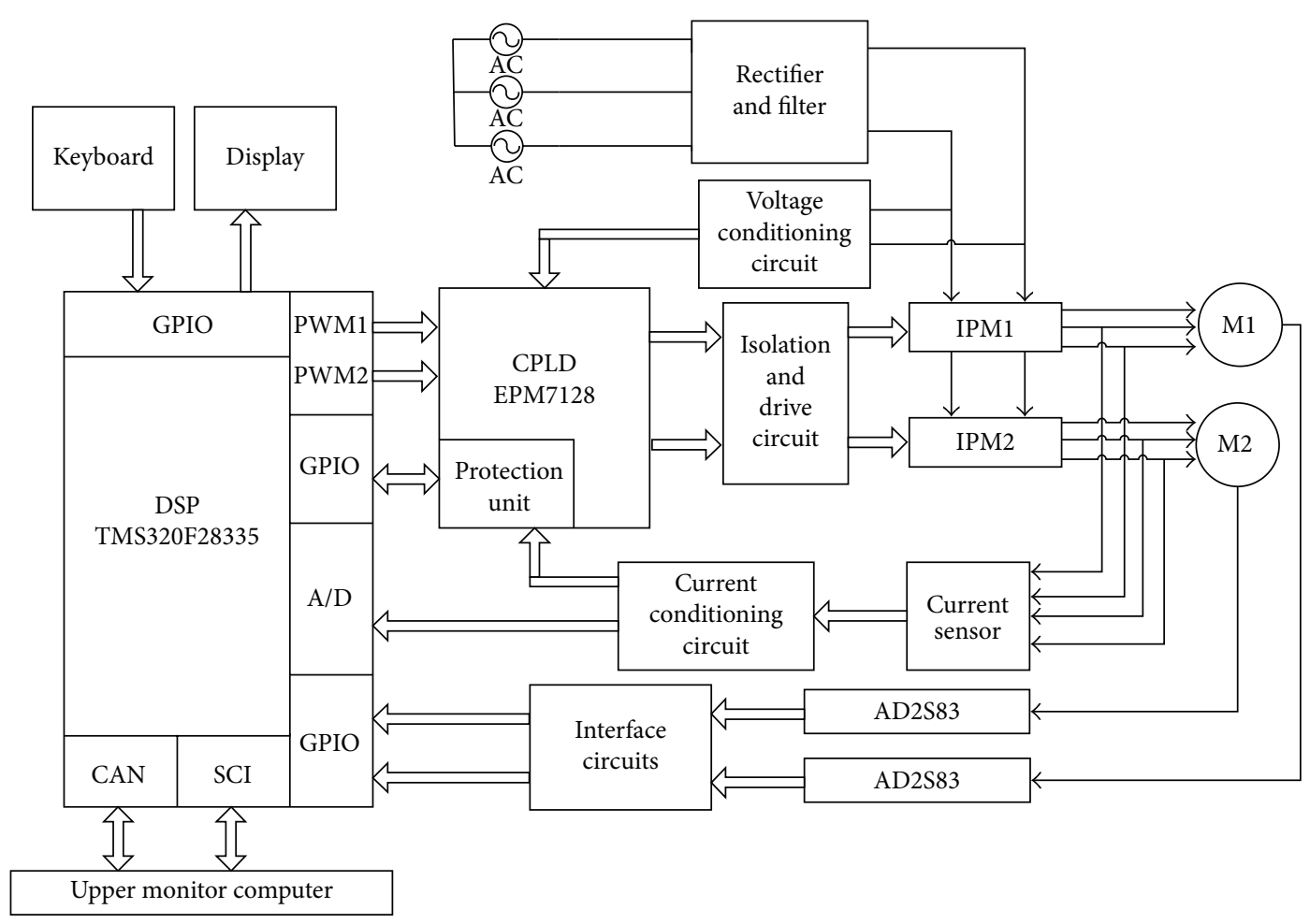

FIgURE 4: Structure of the synchronous control drive.

Proof of Theorem 5. Consider the following Lyapunov function:

$$
V=V_{1}+V_{2}+V_{\varepsilon}=\frac{1}{2} \sigma_{1}^{2}+\frac{1}{2} \sigma_{2}^{2}+\frac{1}{2} \sigma_{\varepsilon}^{2} .
$$

Considering (19), the time derivative of (23) along the system trajectories is given by

$$
\dot{V}=\sigma_{1} \dot{\sigma}_{1}+\sigma_{2} \dot{\sigma}_{2}+\sigma_{\varepsilon}\left(\dot{\sigma}_{1}-\dot{\sigma}_{2}\right)
$$

Substituting (10), (14), and (22) into (23), one obtains

$$
\begin{gathered}
\dot{V}=\sum_{i=1}^{2} \sigma_{i}\left(r \dot{e}_{i}+a_{i} \dot{u}_{i n}+w_{i}+a_{i} \dot{u}_{i s}\right) \\
+\sigma_{\varepsilon}\left(r \dot{e}_{1}+a_{1} \dot{u}_{1 n}+w_{1}+a_{1} \dot{u}_{1 s}-r \dot{e}_{2}\right. \\
\left.\quad-a_{2} \dot{u}_{2 n}-w_{2}-a_{2} \dot{u}_{2 s}\right) .
\end{gathered}
$$

Substituting (11) into (25) yields

$$
\begin{aligned}
\dot{V}=\sum_{i=1}^{2} \sigma_{i}\left[-k \sigma_{i}-\rho_{i} \operatorname{sgn}\left(\sigma_{i}\right)+w_{i}+a_{i} \dot{u}_{i s}\right] \\
+\sigma_{\varepsilon}\left[-k\left(\sigma_{1}-\sigma_{2}\right)-\rho_{1} \operatorname{sgn}\left(\sigma_{1}\right)+w_{1}\right. \\
\left.\quad+\rho_{2} \operatorname{sgn}\left(\sigma_{2}\right)-w_{2}+a_{1} \dot{u}_{1 s}-a_{2} \dot{u}_{2 s}\right] .
\end{aligned}
$$

By (17) and (19), it follows that

$$
\begin{aligned}
\dot{V} \leq & -k\left(\sigma_{1}^{2}+\sigma_{2}^{2}+\sigma_{\varepsilon}^{2}\right)+a_{1} \dot{u}_{1 s} \sigma_{1}+a_{2} \dot{u}_{2 s} \sigma_{2} \\
& +a_{1} \dot{u}_{1 s} \sigma_{\varepsilon}-a_{2} \dot{u}_{2 s} \sigma_{\varepsilon}+2\left(\rho_{1}+\rho_{2}\right)\left|\sigma_{\varepsilon}\right| .
\end{aligned}
$$

By (21), inequality (27) can be rewritten as

$$
\begin{aligned}
\dot{V} \leq & -k\left(\sigma_{1}^{2}+\sigma_{2}^{2}+\sigma_{\varepsilon}^{2}\right) \\
& -\frac{1}{3}\left[k_{\varepsilon} \sigma_{\varepsilon}+\frac{3}{2} \rho_{\varepsilon} \cdot \operatorname{sgn}\left(\sigma_{\varepsilon}\right)\right] \cdot\left(\sigma_{1}-\sigma_{2}\right) \\
& -\frac{2}{3}\left[k_{\varepsilon} \sigma_{\varepsilon}+\frac{3}{2} \rho_{\varepsilon} \cdot \operatorname{sgn}\left(\sigma_{\varepsilon}\right)\right] \sigma_{\varepsilon}+2\left(\rho_{1}+\rho_{2}\right)\left|\sigma_{\varepsilon}\right| \\
= & -k \sigma_{1}^{2}-k \sigma_{2}^{2}-\left(k+k_{\varepsilon}\right) \sigma_{\varepsilon}^{2}-\frac{1}{2} \rho_{\varepsilon}\left|\sigma_{\varepsilon}\right|+2\left(\rho_{1}+\rho_{2}\right)\left|\sigma_{\varepsilon}\right| \\
& -\rho_{\varepsilon}\left|\sigma_{\varepsilon}\right| \\
\leq & -k \sigma_{1}^{2}-k \sigma_{2}^{2}-\left(k+k_{\varepsilon}\right) \sigma_{\varepsilon}^{2} .
\end{aligned}
$$

From (28), it can be obtained that the closed-loop system is asymptotically stable. Further considering (8) and (20), it is deduced that $\lim _{t \rightarrow \infty}\left|e_{i}\right|=0$ and $\lim _{t \rightarrow \infty}|\varepsilon|=0$. Thus, the designed control laws can assure the speed tracking and synchronization performance in spite of uncertainties and perturbations. The convergence rate of the speed tracking errors and the synchronization error depends on the constants $r, k$, and $k_{\varepsilon}$.

\section{Experimental Results}

To simplify the system structure and facilitate the implementation of the suggested control scheme, a DSP (TMS320F28335) and CPLD (EPM7128) based dual-motor 
synchronous control drive is designed, which can control two motors simultaneously. The structure of the drive is shown in Figure 4. The DSP is running at $150 \mathrm{MHZ}$; it collects motor information (velocity/current), executes synchronous control scheme, and drives the two motors in each $1 \mathrm{~ms}$ timer interrupt service program. The CPLD is mainly used for protecting drive circuits; when some emergency occurs, the PWM waveforms will soon be blocked by CPLD, and a fault signal will be generated and sent to DSP.

The experimental system (Figure 5) is composed of an upper computer, a drive, and two PMSMs produced by Kollmorgen (Model: M-403-B). The upper computer and the drive are connected through a CAN bus. In the running process, the upper computer sends speed commands to the drive and keeps watching the motor states. The parameters of the motors are listed in Table 1.

A $1000 \mathrm{rpm}$ step signal is considered as the reference, and it is processed by a filter, whose transfer function is $G(s)=$ $1 /(0.04 s+1)$. For the sake of comparison, the experiment is implemented twice using a conventional PI controller with a synchronous error feedback element $(\mathrm{PI}+\mathrm{SEF})$ and the proposed scheme, respectively. The control law of PI + SEF is expressed as

$$
\begin{array}{r}
u_{i}=K_{p}\left(x_{d}-x_{i}\right)+K_{i} \int\left(x_{d}-x_{i}\right) d t+(-1)^{i} K_{s}\left(x_{1}-x_{2}\right), \\
i=1,2 .
\end{array}
$$

The parameters of the two controllers are listed in Table 2; they are properly chosen based on the criterion that the system can get similar performance using different controllers under normal conditions, and they keep constant during the whole test. The two motors firstly work in nonload status (Figure 6). From Figures 8(a) and 8(c), it can be found that the tracking curves are quite similar for both controllers, the regulation time of the system is $0.1 \mathrm{~s}(\Delta= \pm 2 \%)$, there is no obvious overshoot, the two motors keep their speed the same at the startup stage, and both controllers can achieve high performance.

Next is the unbalanced load test; motor 1 is mounted on a fixed base and drives a $3.5 \mathrm{~N} \cdot \mathrm{m}$ load while motor 2 is on the ground and works in nonload status (Figure 7). The asynchronous situation appears at the startup stage when using the PI + SEF scheme; the maximum synchronous error reaches $280 \mathrm{rpm}$, and the regulation time of the system slows down to $0.2 \mathrm{~s}$ (Figure 9(a)). When the proposed scheme is applied, however, the two motors keep their speed the same from the beginning to the end, and the regulation time is still 0.1s (Figure 9(c)). The proposed synchronous control method demonstrates good robustness with respect to load uncertainties.

To conduct the disturbance suppression ability test for both control schemes, a $-2 \mathrm{~A}$ filtered step signal is added to the current command of motor 1 at $1.5 \mathrm{~s}$. It can be found in Figures 10(b) and 10(d) that both controllers give response to the disturbance, but the proposed controllers give a more rapid response. After the disturbance is added, the velocity of motor 1 decreases by $48 \mathrm{rpm}$ using PI + SEF

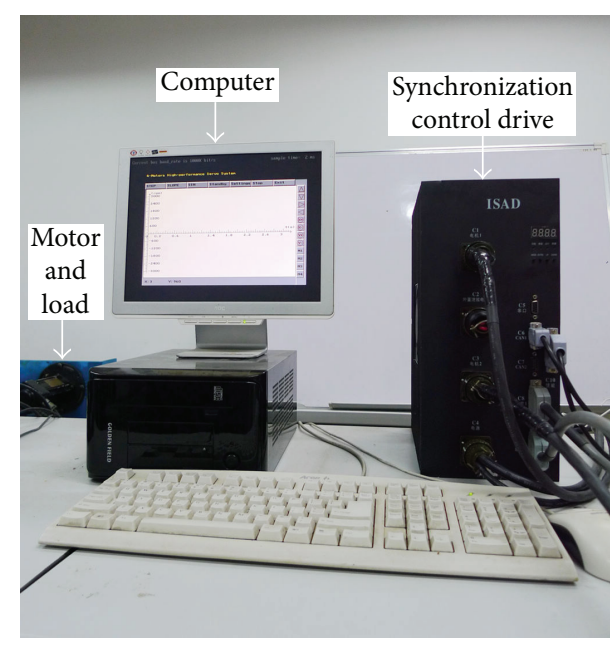

FIgURE 5: Experimental system.

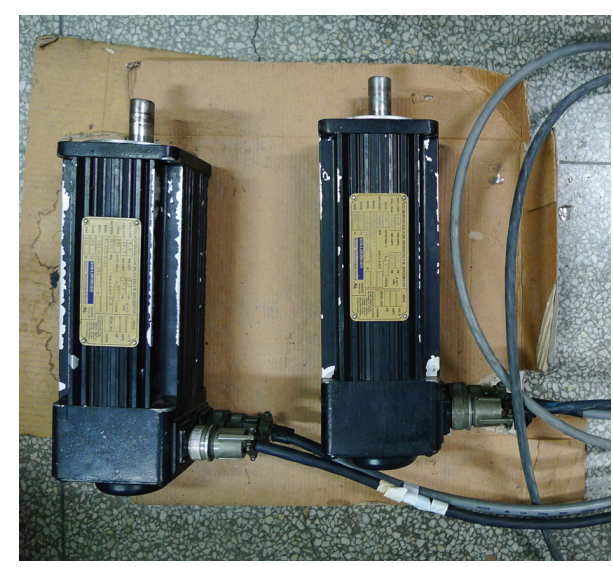

FIGURE 6: Two motors work in nonload status.

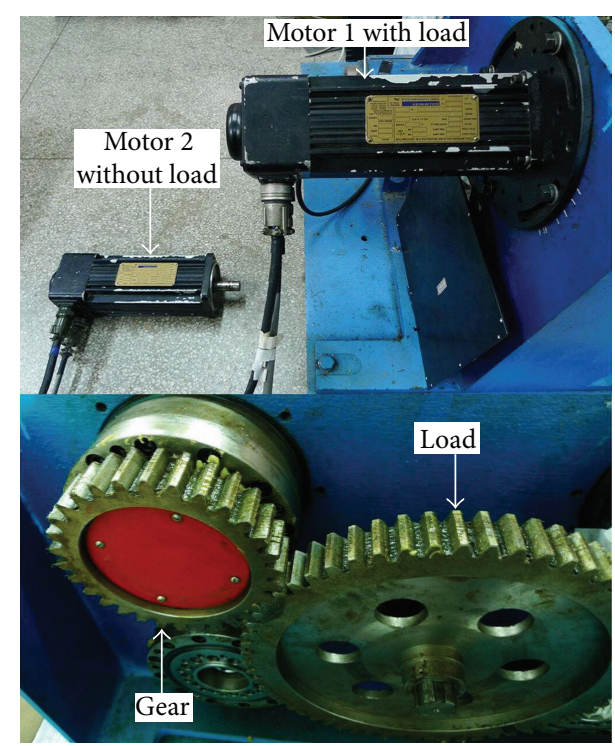

FIGURE 7: Two motors work in unbalanced load status. 


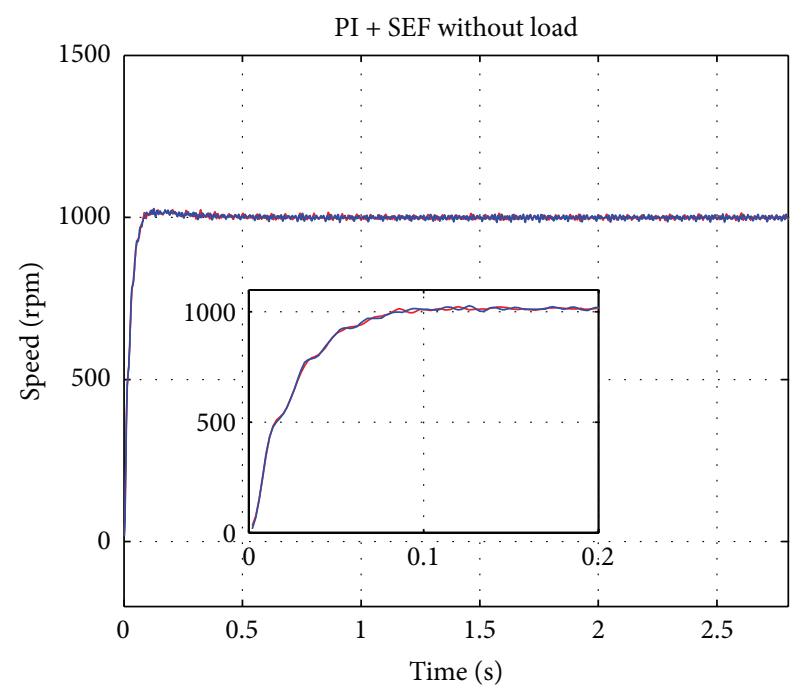

(a) Speed response $(\mathrm{PI}+\mathrm{SEF})$

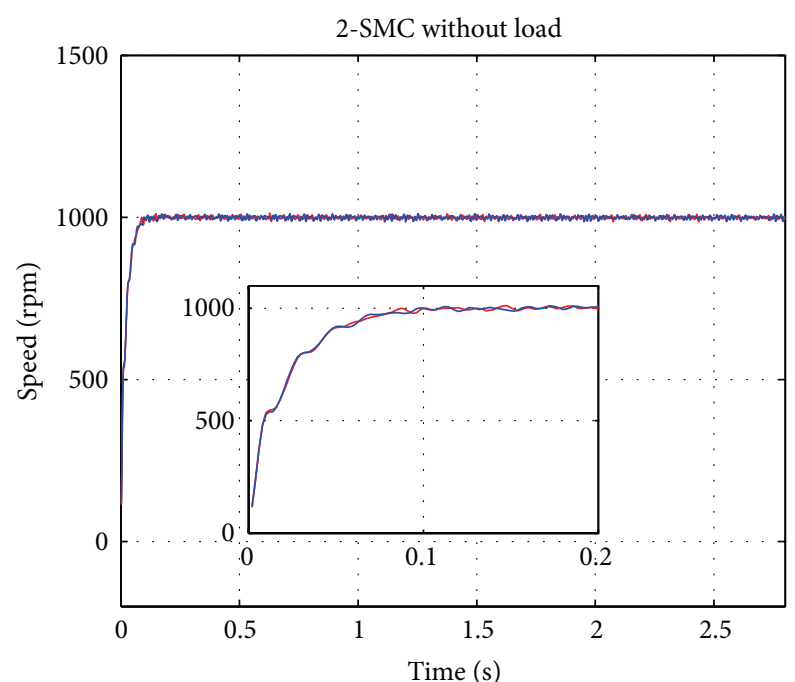

Motor 1

Motor 2

(c) Speed response (2-SMC)

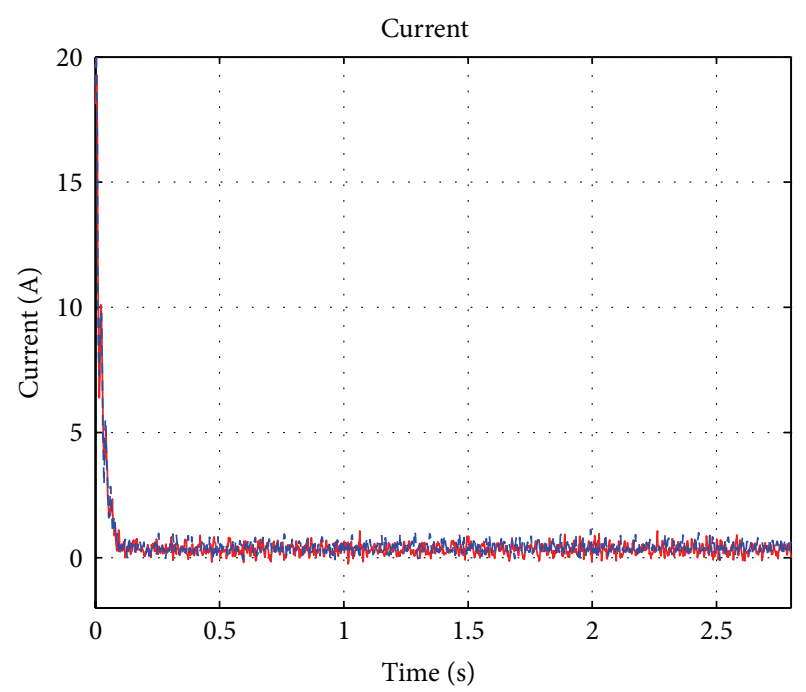

(b) Current response $(\mathrm{PI}+\mathrm{SEF})$

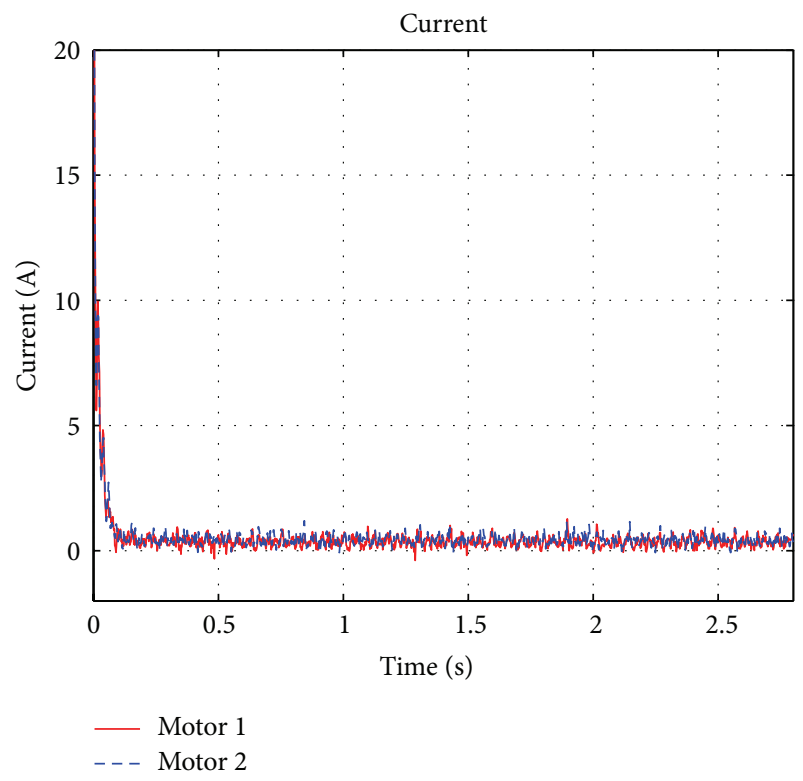

(d) Current response (2-SMC)

FIGURE 8: System response in nonload status.

TABLE 1: Motor parameters.

\begin{tabular}{lc}
\hline Parameter & Value \\
\hline Rated power/kW & 2.2 \\
Rated current/A & 6.4 \\
Rated speed $/ \mathrm{rpm}$ & 3000 \\
Torque constant $/ \mathrm{Nm} \cdot \mathrm{A}^{-1}$ & 1.11 \\
Inertia $/ \mathrm{kg} \cdot \mathrm{m}^{2}$ & 0.00259 \\
Static friction $/ \mathrm{Nm}$ & 0.24 \\
Viscous damping Nm/krpm & 0.015 \\
Number of poles & 4 \\
\hline
\end{tabular}

TABLE 2: Controller parameters.

\begin{tabular}{lc}
\hline PI + SEF & Value \\
\hline$K_{p}$ & 3.6 \\
$K_{i}$ & 0.02 \\
$K_{s}$ & 1.1 \\
\hline 2 -SMC & Value \\
\hline$r$ & 2 \\
$k$ & 0.03 \\
$k_{\varepsilon}$ & 0.02 \\
$\rho$ & 12 \\
\hline
\end{tabular}




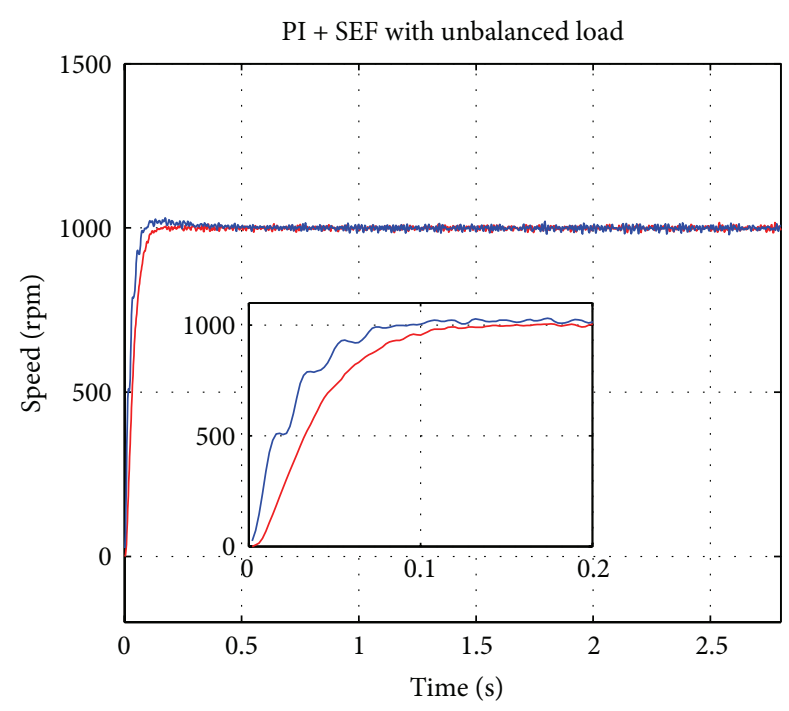

(a) Speed response $(\mathrm{PI}+\mathrm{SEF})$

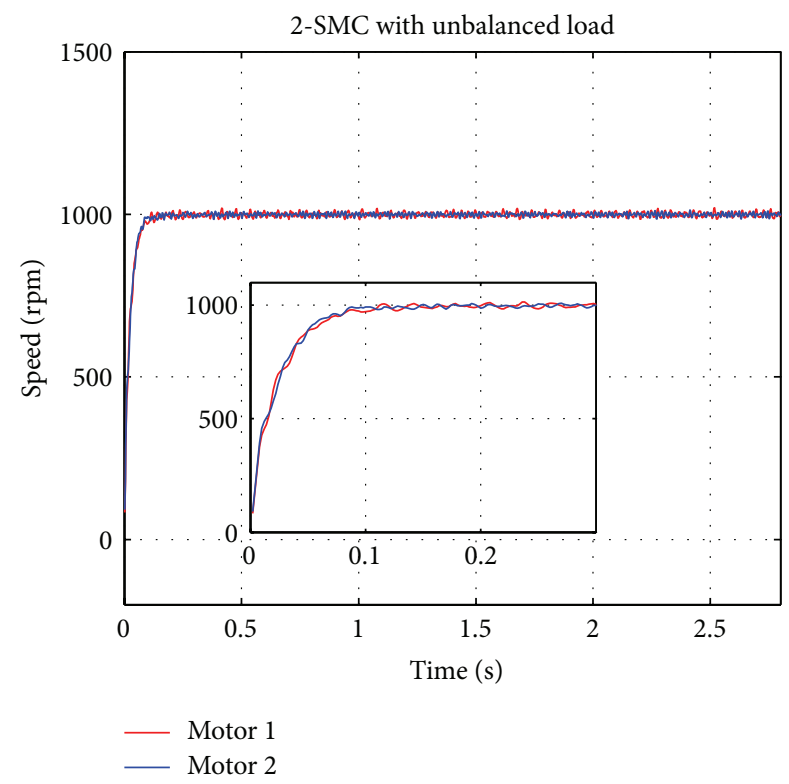

(c) Speed response (2-SMC)

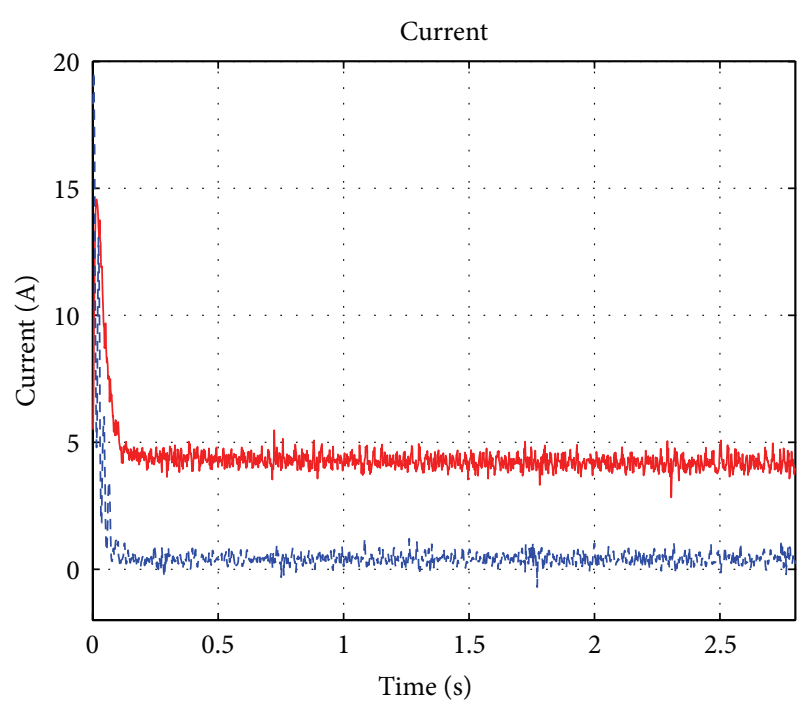

(b) Current response (PI + SEF)

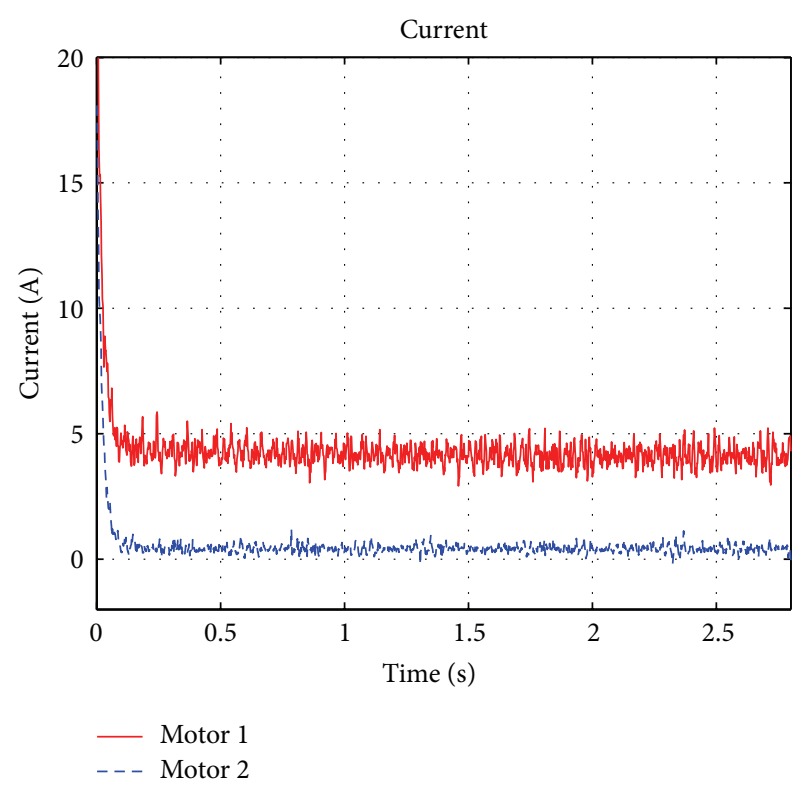

(d) Current response (2-SMC)

FIGURE 9: System response in unbalanced load status.

method, asynchronous situation appears, and the maximum synchronous error reaches $40 \mathrm{rpm}$ (Figure 10(a)). Applying the proposed method, the velocity of motor 1 only decreases by $13 \mathrm{rpm}$ and the two motors still keep their speed the same (Figure 10(c)).

All experiments are done using the fixed preset controller parameters; it can be obtained from the previous results that the suggested dual-motor synchronous control scheme shows superior robustness compared with the conventional $\mathrm{PI}+\mathrm{SEF}$ control method. When variations and disturbances appear in the system, it can still assure the speed tracking and synchronization performance of the motors.

\section{Conclusions}

This paper has presented a 2-SM based synchronous control scheme for dual-motor systems. Single axis speed controller and synchronous controller, which can assure the asymptotical stability of the closed-loop system, have been developed, respectively. The proposed scheme has been evaluated in terms of speed tracking and synchronization performance (robustness against load uncertainties and perturbations) by experiments. The results have shown the superior robustness of the suggested scheme with respect to the conventional PI + SEF control method, at least when unbalanced load torque or disturbances are applied to the two motors. 


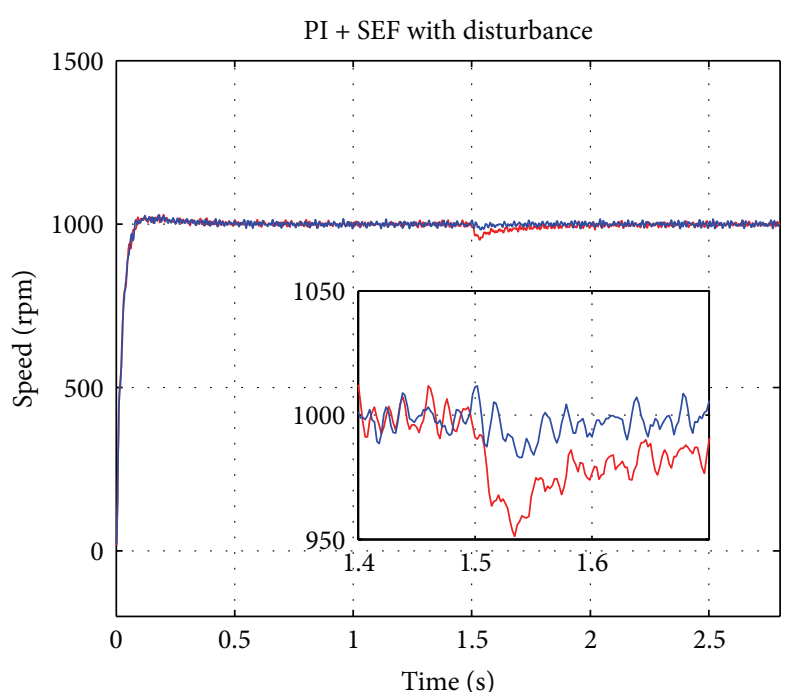

- Motor 1

- Motor 2

(a) Speed response $(\mathrm{PI}+\mathrm{SEF})$

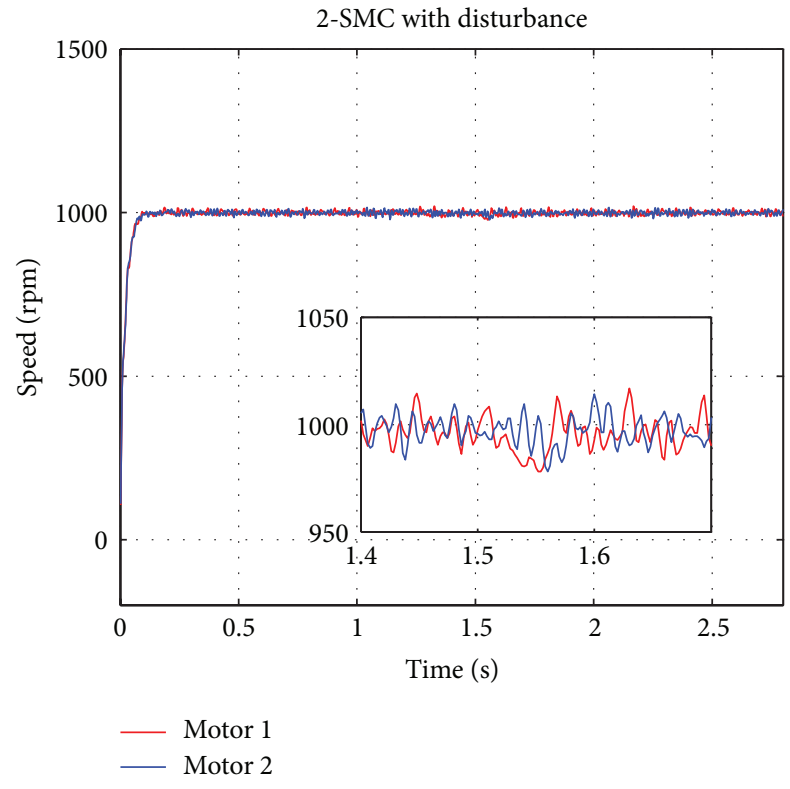

(c) Speed response (2-SMC)

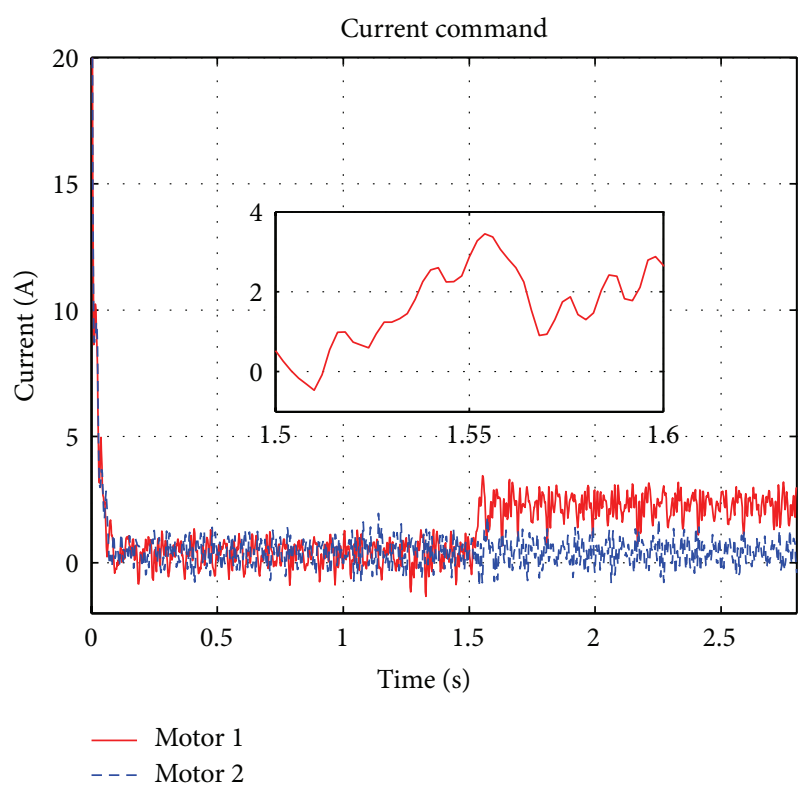

(b) Current command (PI + SEF)

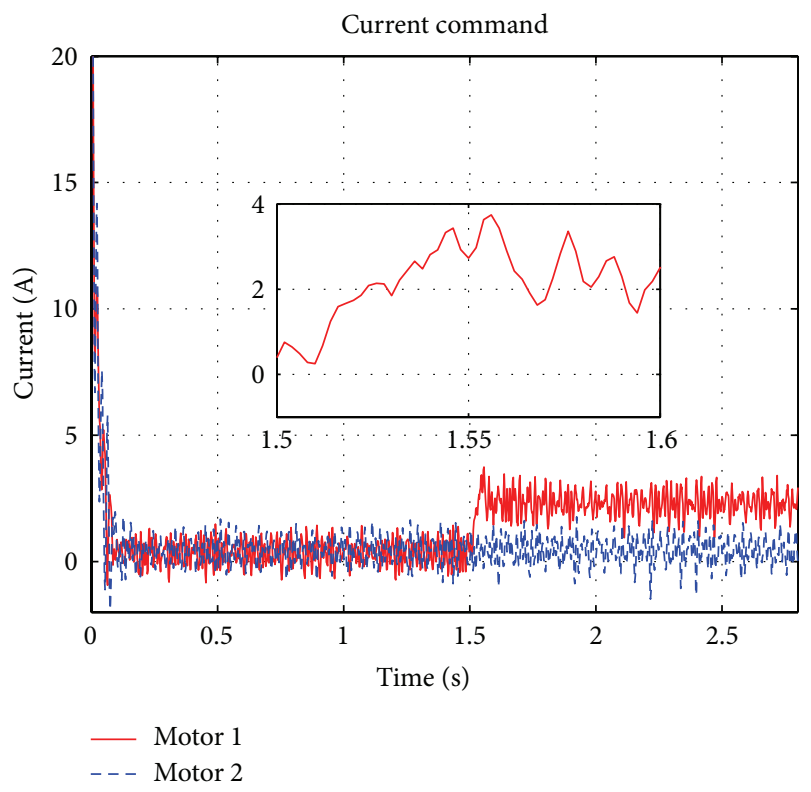

(d) Current command (2-SMC)

FIGURE 10: System response under current command disturbance.

\section{Acknowledgments}

This project is supported by the National Natural Science Foundation of China (Grant no. 61074023) and Graduate Student Research and Innovation Program of Jiangsu Province (CXLX11_0256).

\section{References}

[1] C.-W. Chuang, C.-L. Haung, C.-D. Lee, C.-C. Kao, and R.F. Fung, "Synchronization and tension control of dual motor systems via MIMO discrete pseudo model following integral variable structure control," Mechanism and Machine Theory, vol. 44, no. 2, pp. 499-510, 2009.

[2] P.-H. Chou, C.-S. Chen, and F.-J. Lin, "DSP-based synchronous control of dual linear motors via Sugeno type fuzzy neural network compensator," Journal of the Franklin Institute, vol. 349, no. 3, pp. 792-812, 2012.

[3] Y. Xiao and K. Y. Zhu, "Optimal synchronization control of high-precision motion systems," IEEE Transactions on Industrial Electronics, vol. 53, no. 4, pp. 1160-1169, 2006.

[4] G. T.-C. Chiu and M. Tomizuka, "Coordinated position control of multi-axis mechanical systems," ASME Journal of Dynamic Systems, Measurement and Control, vol. 120, no. 3, pp. 389-393, 1998. 
[5] F. J. Perez-Pinal, C. Nunez, R. Alvarez, and I. Cervantes, "Comparison of multi-motor synchronization techniques," in Proceedings of the 30th Annual Conference of the IEEE Industrial Electronics Society, pp. 1670-1675, Busan, Korea, November 2004.

[6] Y. Koren, "Cross-coupled biaxial computer controls for manufacturing systems," ASME Journal of Dynamic Systems, Measurement and Control, vol. 102, no. 4, pp. 265-272, 1980.

[7] D. Sun, "Position synchronization of multiple motion axes with adaptive coupling control," Automatica, vol. 39, no. 6, pp. 9971005, 2003.

[8] K. L. Barton and A. G. Alleyne, "A cross-coupled iterative learning control design for precision motion control," IEEE Transactions on Control Systems Technology, vol. 16, no. 6, pp. 1218-1231, 2008.

[9] F.-J. Lin, H.-J. Hsieh, P.-H. Chou, and Y.-S. Lin, "Digital signal processor-based cross-coupled synchronous control of dual linear motors via functional link radial basis function network," IET Control Theory and Applications, vol. 5, no. 4, pp. 552-564, 2011.

[10] L. Wu and W. X. Zheng, "Passivity-based sliding mode control of uncertain singular time-delay systems," Automatica, vol. 45, no. 9, pp. 2120-2127, 2009.

[11] L. Wu and D. W. C. Ho, "Sliding mode control of singular stochastic hybrid systems," Automatica, vol. 46, no. 4, pp. 779$783,2010$.

[12] L. G. Wu, X. J. Su, and P. Shi, "Sliding mode control with bounded L2 gain performance of Markovian jump singular time-delay systems," Automatica, vol. 48, no. 8, pp. 1929-1933, 2012.

[13] L. Wu, P. Shi, and H. Gao, "State estimation and slidingmode control of Markovian jump singular systems," IEEE Transactions on Automatic Control, vol. 55, no. 5, pp. 1213-1219, 2010.

[14] L. G. Wu, W. X. Zheng, and H. J. Gao, "Dissipativity-based sliding mode control of switched stochastic systems," IEEE Transactions on Automatic Control, vol. 58, no. 3, pp. 785-793, 2013.

[15] S. V. Emel'yanov, S. V. Korovin, and L. V. Levantovsky, "Higher order sliding modes in the binary control system," Soviet Physics Doklady, vol. 31, pp. 291-293, 1986.

[16] W. Perruquetti and J. P. Barbot, Sliding Mode Control in Engineering, Marcel Dekker, NY, New York, USA, 2002.

[17] M. Defoort, T. Floquet, A. Kökösy, and W. Perruquetti, "Slidingmode formation control for cooperative autonomous mobile robots," IEEE Transactions on Industrial Electronics, vol. 55, no. 11, pp. 3944-3953, 2008.

[18] M. Canale, L. Fagiano, A. Ferrara, and C. Vecchio, "Vehicle yaw control via second-order sliding-mode technique," IEEE Transactions on Industrial Electronics, vol. 55, no. 11, pp. 39083916, 2008.

[19] A. Pisano, A. Davila, L. Fridman, and E. Usai, "Cascade control of PM DC drives via second-order sliding-mode technique," IEEE Transactions on Industrial Electronics, vol. 55, no. 11, pp. 3846-3854, 2008.

[20] M. Defoort, F. Nollet, T. Floquet, and W. Perruquetti, "A third-order sliding-mode controller for a stepper motor," IEEE Transactions on Industrial Electronics, vol. 56, no. 9, pp. 33373346, 2009. 


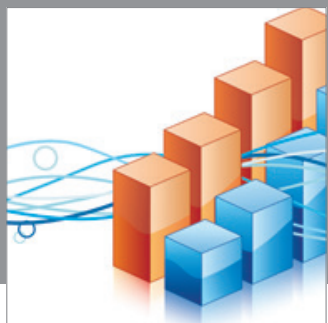

Advances in

Operations Research

mansans

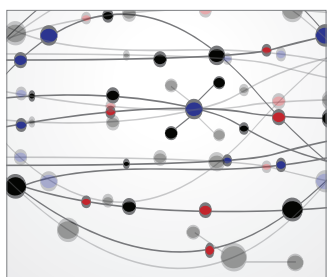

The Scientific World Journal
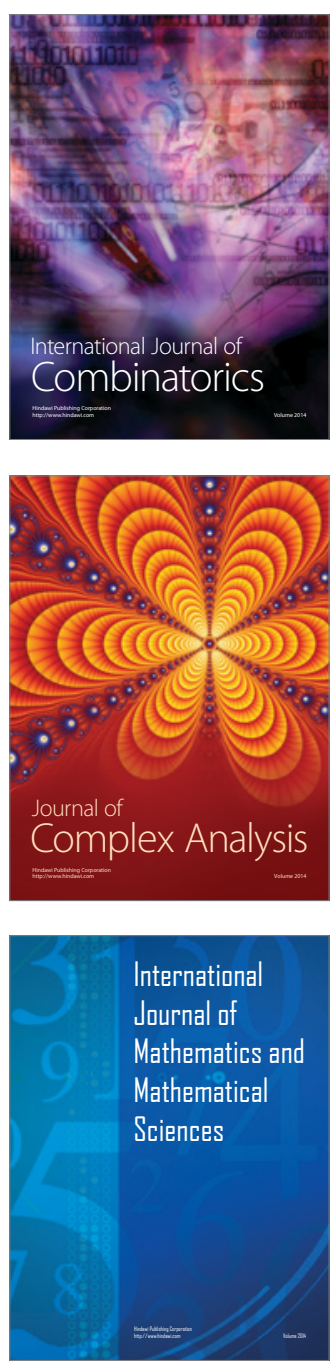
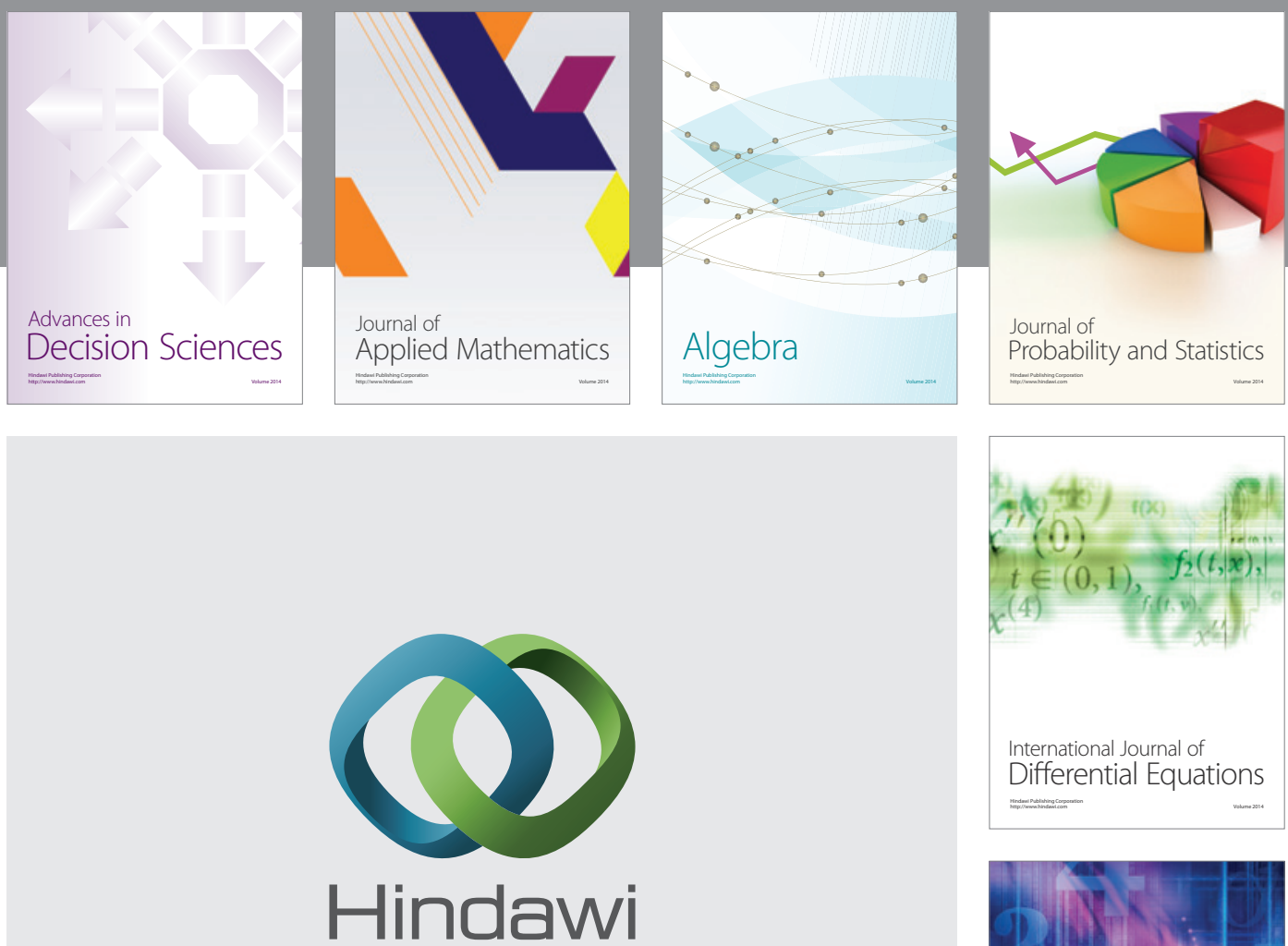

Submit your manuscripts at http://www.hindawi.com
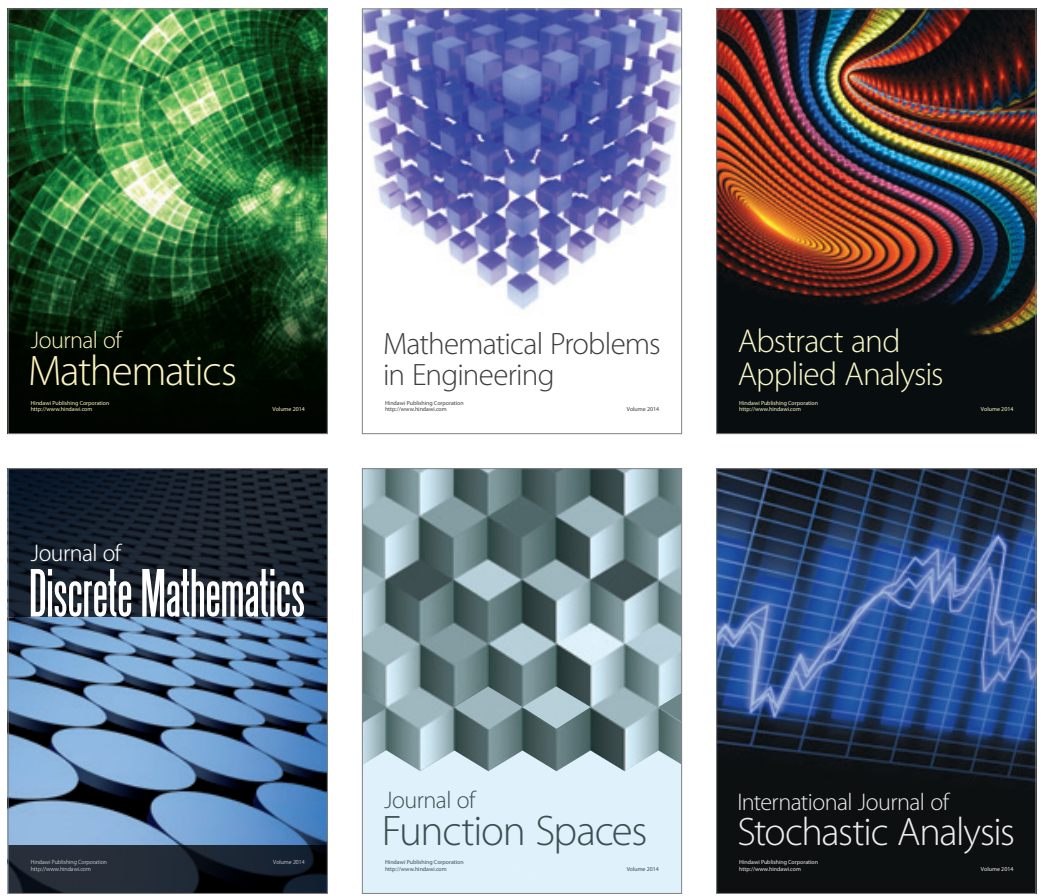

Journal of

Function Spaces

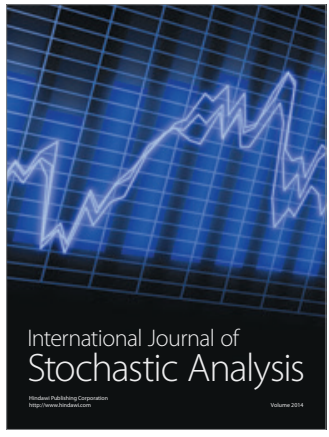

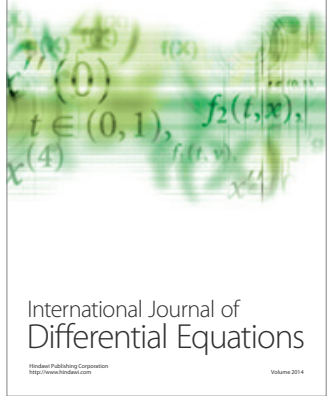
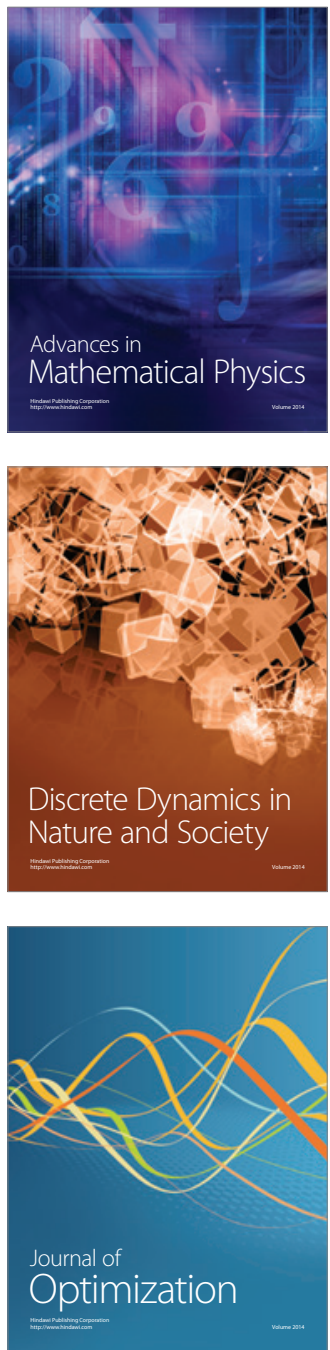